\title{
The structure of IL2 bound to the three chains of the IL2 receptor and how signaling occurs Kendall A Smith*
}

\author{
Address: The Division of Immunology, Department of Medicine, Weill Medical College, Cornell University, New York, NY, 10021, USA \\ Email: Kendall A Smith* - kasmith@med.cornell.edu \\ * Corresponding author
}

Published: 14 August 2006

Medical Immunology 2006, 5:3 doi:10.1 186/1476-9433-5-3

This article is available from: http://www.medimmunol.com/content/5/I/3

C) 2006 Smith; licensee BioMed Central Ltd.

This is an Open Access article distributed under the terms of the Creative Commons Attribution License (http://creativecommons.org/licenses/by/2.0), which permits unrestricted use, distribution, and reproduction in any medium, provided the original work is properly cited.
Received: 20 July 2006

Accepted: 14 August 2006

\begin{abstract}
The interleukin- 2 molecule and receptor were the first of the interleukins to be discovered and characterized at the molecular level. Now after 20 years of effort, two groups have succeeded in determining the structure of IL2 bound to the external domains of the three receptor chains in a quaternary complex. What do we know now that we did not know before this structural information was available, and how do these new data help us to develop new therapies?
\end{abstract}

In the early 1980s, soon after we had characterized the IL2 molecule as a $15.5 \mathrm{kDa}$ variably glycosylated protein[1,2], had purified it to homogeneity[2], and had discovered and characterized the IL2 receptor (IL2R)[3], our attention turned to trying to determine exactly how IL2 binding to its receptor leads to signals that promote cellular proliferation. One approach to this question involved determining the 3-dimensional (3D) structures of the IL2 molecule and the IL2R via X-ray crystallography. However, it took more than a decade for us and others to discover that the IL2R is comprised of three distinct noncovalently linked chains, termed alpha $(\alpha, \mathrm{CD} 25)[4]$, beta $(\beta$, CD122) [5-7], and gamma $(\gamma$, CD132)[8]. Subsequently, as the cDNAs encoding each chain became available, we began to collaborate with Ian Wilson of the Scripps Research Institute to try to determine the structures of these molecules. Instrumental in these experiments was Tom Ciardelli at Dartmouth, who constructed expression systems to produce large amounts of the proteins to be used in obtaining crystals of the molecules, which he also used in rigorous reduction experiments with binding studies using isolated soluble receptor molecules.
Anything is possible in science, but some things take a very long time. Indeed, crystals of IL2 bound to the IL2R $\alpha$ chain were readily achieved as early as 1989 [9], but they remained recalcitrant to structure solution for many years. Moreover, the fact that the IL2R is comprised of three separate chains made the task of crystallizing all four proteins bound together exceedingly difficult. Twenty years after our experiments were initiated, Chris Garcia at Stanford with his team of two talented post docs, Xinquan Wang and Mathias Rickert, succeeded in determining the structure of IL2 bound to the external domains of the three IL2R chains in a quaternary complex[10]. Chris is a former postdoc of Ian Wilson, and he generously shared their refined coordinates with Ian, so that two other talented members of Ian's group, postdoc Deborah Stauber and graduate student Erik Debler, could finish the structure determination of the IL2/IL2R quaternary complex, which they also had also assembled and crystallized[11].

Before examining the new data, it is useful to summarize the information that we have gained over the past 25 years as to how the IL2/IL2R ligand/receptor complex functions. IL2 itself is a small globular glycoprotein comprised 
of four antiparallel $\alpha$ helices[12]. IL2 was the first cytokine found to mediate its effects via a cell surface binding site that satisfied all of the requirements to be termed a classic hormone receptor, originally defined by Langely in 1878 and 1905[13,14]. Thus, IL2 binds to the IL2R with high affinity, stereospecificity, and saturability. In other words, there are a finite number of sites expressed on activated lymphocytes that are capable of binding only IL2, among all of the other cytokines. In addition, IL2 signals the cell at the same low concentrations that lead to binding to the IL2R at steady state, thus satisfying the requirement that true receptors must signal a physiological response after binding the ligand at physiological concentrations. The question before us is how these classic receptor characteristics are created at the molecular level.

The high affinity of the IL2R $\left(\mathrm{K}_{\mathrm{d}}=10^{-11} \mathrm{M}\right)$ results from a rapid association rate contributed by the $\alpha$-chain $\left(\mathrm{k}_{\mathrm{on}}=\right.$ $10^{7} \mathrm{M}^{-1} \mathrm{sec}^{-1}$ ), combined with a relatively slow dissociation rate $\left(\mathrm{k}_{\text {off }}=10^{-4} \mathrm{sec}^{-1}\right)$ contributed by both the $\beta$ and $\gamma$ chains $[15,16]$. Accordingly, from this information, it was concluded that distinct areas of the IL2 molecule bind to each of the three receptor chains. Moreover, it was also found that the $\alpha$ chain does not participate in signaling, whereas both the $\beta$ and $\gamma$ chains are necessary for signaling $[17,18]$. One of the perplexing aspects of the SAR of IL2/IL2R binding was the contribution of the $\gamma$ chain, in that it was discovered that the $\gamma$ chain is a component of several other cytokine receptors, including the IL4R, IL7R, IL9R, IL15R, and the IL21R [19-21]. Exactly how each of these different, although similar, cytokines could actually bind to the same $\gamma$ chain remained an enigma.

A series of reports from the Ciardelli group at Dartmouth over the 1990s using isolated receptor chains and Surface Plasmon Resonance (SPR) dissected the complex relationships between IL2 and the three receptor chains [22-27]). Their data supported a model in which the $\alpha$ and $\beta$ chains pre-associate on the cell surface to form a pseudo-high affinity site with a faster on-rate and a slower off-rate than either of the individual subunits. Thus, the efficiency of ligand capture is facilitated by the formation of this $\alpha / \beta$ chain heterodimer. Moreover, these data are consistent with the IL2-induction of $\alpha$ chain expression[28], which results in a $10-20$-fold excess of $\alpha$ chain vs. $\beta$ chain expression, thereby favoring the formation of an $\alpha / \beta$ heterodimer on the cell surface via the law of mass action.

In addition, their data indicated that signaling only occurs subsequent to the recruitment of the $\gamma$ chain to the IL $2 / \alpha /$ $\beta$ trimeric complex $[25,27]$. Even though the $\gamma$ chain is only weakly able to interact with IL2 by itself $\left(K_{d}>700\right.$ $\mu \mathrm{M})$, when recruited to join the heterotrimer of IL2 bound to the $\alpha / \beta$ heterodimer, the $\gamma$ chain reduces the off-rate of the bound ligand substantially by forming a stable quater- nary ligand/receptor complex. Thus, the model predicted that the mechanism controlling the duration of receptor signaling is the rate of ligand/receptor internalization $\left(\mathrm{t}_{1 /}\right.$ ${ }_{2}=15$ minutes $)$, rather than ligand dissociation $\left(t_{1 / 2}=45\right.$ minutes), as we had proposed originally[29]. This is important, given that the cell counts the total number of triggered IL2Rs, which is responsible for signaling a quantal (all-or-none) cellular response [30-32].

An additional view of how IL2 interacts with the three receptor chains was reported by Garcia's group using Isothermal Titration Calorimetry and Multi-Angle Light Scattering[33]. Even in the absence of IL2, they found low affinity binding of the $\alpha$ and $\beta$ chains $\left(K_{d}=278 \mathrm{nM}\right)$, thereby supporting the Ciardelli SPR studies. Also, similar to Ciardelli's SPR results, there was no binding between the $\alpha$ and $\gamma$ chains or the $\beta$ and $\gamma$ chains in the absence of IL2. Also, similar to previous IL2 binding studies, a definite affinity of IL2 for isolated $\alpha$ chains $\left(K_{d}=10 \mathrm{nM}\right)$ and isolated $\beta$ chains ( $\left.K_{d}=144 \mathrm{nM}\right)$, but little or no affinity for IL2 binding to isolated $\gamma$ chains was found using these thermodynamic techniques. These investigators interpreted their data as consistent with IL2 binding rapidly first to isolated $\alpha$ chains, followed by the $\alpha$-bound IL2 being stabilized by binding to isolated $\beta$ chains. Alternatively, their data were also consistent with IL2 binding to a preformed $\alpha / \beta$ dimeric complex as proposed by Ciardelli. All of the data were consistent with the IL $2 / \alpha / \beta$ trimeric complex binding to the $\gamma$ chain to form the final signaling complex.

The crystallization of IL2 bound to the external domains of the three receptor chains in a quaternary complex $[10,11]$ revealed that the sites on IL2 that interact with the three chains of the IL2R do not overlap, except for a small but significant region, as predicted from the earlier binding and SPR studies. The 4-helix bundle of IL2 is clamped between the elbow regions of the $\beta$ and $\gamma$ chains. The IL2 molecule is held decisively between these two receptor chains, which converge to form a $\mathrm{Y}$ shape, with IL2 bound in the fork of the Y. In contrast, the other side of the IL2 molecule binds to the $\alpha$ chain, which Garcia's team had previously delineated from binary IL2/ $\alpha$ chain crystals[34]. It is also noteworthy that the $\alpha$ chain itself does not contact either the $\beta$ or $\gamma$ chains in the crystal structure.

The crystal structure essentially does not help in discriminating whether IL2 binds first to the $\alpha$ chain alone or to a preformed $\alpha / \beta$ heterodimer. However, the pseudo-high affinity of the IL2 $/ \alpha / \beta$ trimeric complex (i.e. $K_{d} \sim 300 \mathrm{pM}$ ) clearly indicates that the trimeric complex is more stable than either IL2 bound to the $\alpha$ chain alone $\left(K_{d}=10 \mathrm{nM}\right)$ or to the $\beta$ chain alone $\left(K_{d}=450 \mathrm{nM}\right)$ as shown by Ciardelli's data. In any event, the IL $2 / \alpha / \beta$ trimer would 
then recruit the $\gamma$ chain into the quaternary complex capable of signaling, which is facilitated by the large composite binding site on the IL2-bound $\beta$ chain for the $\gamma$ chain. Since only a few residues of IL2 interact with both $\beta$ and $\gamma$ chains, binding of IL2 may induce conformational changes in the $\beta$ chain that would further promote recruitment of the $\gamma$ chain. This interpretation is consistent with data obtained by the Ciardelli group using SPR[27]. Moreover, the surface area of IL2- $\gamma$ chain contact is the smallest of the three receptor chains $\left(970 \AA^{2}\right)$, while the surface area of the $\beta-\gamma$ chain contact is larger $\left(1,640 \AA^{2}\right)$. Accordingly, the $\gamma$ chain can serve as a receptor subunit for many similar but different cytokines by a cytokine-dependent binding of other receptor subunits to the $\gamma$ chain, rather than binding of the cytokines themselves to the $\gamma$ chain. Furthermore these data provide support for the search for inhibitors of the $\beta$ chain- $\gamma$ chain interaction as new immunosuppressants.

All of this structural information is entirely consistent with what we know about IL2R signaling, in that the cytoplasmic domain of the $\beta$ chain is complexed with the JAK1 tyrosine kinase, while the $\gamma$ chain cytoplasmic domain is complexed with the JAK3 kinase[18]. Thus, only when IL2 binding brings the external domains of these two receptor chains into close proximity, can signaling occur by trans phosphorylation of their cytoplasmic domains. In addition, as emphasized by Ciardelli's SPR data and by Garcia's energetics data, these structural data indicate that the quaternary ligand/receptor complex is very stable and signaling will continue until the receptor with bound ligand is internalized and degraded.

In the context of all of these new structural data, an earlier report from Marrack's group[35] is perplexing, in that it showed that the injection of mice with monoclonal antibodies $(\mathrm{mAb})$ reactive with IL2 that block the IL2/IL2R $\alpha$ chain interaction, thereby inhibiting IL2-promoted $T$ cell proliferation in vitro, actually increased the number of proliferating CD8 + T cells in vivo, instead of decreasing them as expected. These authors interpreted their results as showing that IL2 functioned to actually kill CD8+ T cells in vivo. Of course this interpretation is based upon the assumption that the anti-IL2 should have blocked IL2- $\alpha$ chain binding and $\mathrm{T}$ cell activation in vivo, as it did in vitro.

Now, a more recent report from Sprent's group[36] returned to this paradox; i.e. that the proliferation of CD8+ T cells with a memory phenotype (defined by a high expression of the IL2R $\beta$ chain, but low or absent levels of the IL2R $\alpha$ chain), can be increased by injecting either IL2 itself or an IL2-reactive, inhibitory mAb. Since the interpretation by Marrack's group was counterintuitive, Sprent repeated their experiments, and also found an increase in CD8+ T cells using the same mAb. However, in addition, they used IL2 gene deleted mice, and found that the enhanced proliferative effect of the anti-IL2 treatment was abolished in this setting.

Consequently, they then hypothesized that perhaps the IL2-reactive mAb functioned to actually increase biological activity of endogenous IL2 via the formation of immune complexes with IL2, thereby preserving and promoting IL2 activity. This was in fact found to be the case, and the simultaneous administration of IL2 and IL2-reactive $\mathrm{mAb}$ resulted in a dramatic increase ( $>100$-fold) in the total numbers of CD8+ T cells, and NK cells as well, which also express both the $\beta$ chain and the $\gamma$ chain of the IL2R.

On the basis of these data and others, Sprent concluded that the stimulatory IL2-reactive mAb binds to a site on IL2 that occludes its binding to the $\alpha$ chain, but does not impair binding to the $\beta$ chain. In other words, the IL2reactive MoAb takes the place of the $\alpha$ chain on cells in vivo, and presents IL2 to the $\beta$ and $\gamma$ chains, thereby stimulating proliferation, particularly of memory CD8+ T cells that already express the $\beta / \gamma$ chains as part of the IL15R. In light of the new structural data, Sprent's interpretation makes perfect sense. In addition, as $\mathrm{Fab}_{2}$ fragments of the IL2/mAb complex were inefficient in promoting in vivo $\mathrm{T}$ cell proliferation, these findings are consistent with IL2/ mAb immune complexes on APCs substituting for the cell-bound $\alpha$ chain on $\mathrm{T}$ cells serving as a ligand carrier and/or capturer, as suggested by Stauber et. al. [11].

If further investigation supports these findings, the use of cytokine immune complexes as immune stimulants could very well markedly improve immunostimultatory therapy, in that the cytokine immune complexes have a much improved in vivo half-life compared with cytokines alone. For example, the half-life of IL2 administered intravenously is only $\sim 10$ minutes due to distribution into the total body extracellular space, which is large, $\sim 15 \mathrm{~L}$ in an average sized adult. Subsequently, IL2 is metabolized by the kidneys with a half-time of $\sim 2.5$ hours. By comparison the in vivo half-life of administered Ig is measured in several days if not weeks[37].

Still left obscure regarding the function of the quaternary IL2/IL2R complex is the exact molecular rearrangements that occur in the intracytoplasmic domains of the IL2R chains, especially the $\beta$ and $\gamma$ chains, in that these domains have not yet been crystallized. Thus far, all efforts to date to crystallize these domains have been fruitless, and may indicate that the cytoplasmic tails do not adopt a permanent well-defined structure, which is a prerequisite for crystallization. However, two additional new reports on signaling from the intracytoplasmic domains 
via the JAKS to STAT5a/b have recently underscored the importance of these intracellular domains $[38,39]$.

All of the cytokines that utilize the IL2R common $\gamma$ chain $\left(\gamma_{c}\right)$, have been found to be critical both for their function in the periphery after maturation, and for lymphoid development as well. In particular, mutations of the IL7R $\alpha$ chain, or the $\gamma_{c}$ chain, or its associated kinase, JAK3, are the major causes of human severe combined immunodeficiency (SCID)[18]. Three signaling pathways are known to be activated via the $\gamma c$ chain, the Ras/Raf/MAPK pathway[40], the PI3K/Akt pathway[41], and the STAT5 pathway[42]. All evidence pointed to the STAT5a/b molecules as being the primary signalers of lymphocyte development as well as being critical for promoting cell cycle progression of mature lymphocytes. However, the importance of STAT5a/b in transmitting signals from IL7Rs to developing lymphocytes became controversial, primarily because mice that had a deletion of the $\mathrm{N}$-terminal exon of the STAT5a/b molecules had relatively normal lymphocyte development[43]. However, these mice still expressed a truncated and partially functional STAT5 protein.

Now, utilizing mice that had total deletions of the entire STAT5a/b loci, John O'Shea's group[38] and Veronika Sexl's group[39] have both reported that the phenotype of these mice is as expected, severe combined immunodeficiency. In addition, Sexl's group reports that these mice are not susceptible to malignant transformation by the Src family kinase, Abelson. This last finding is extremely important, for it provides the missing link between the Src family kinases and transformation that has eluded investigators for over 25 years. In addition, these data are consistent with the known functions of STAT5, to activate the program for cell cycle progression through $G_{1}$ to S-phase, primarily by promoting the expression and activity of the $G_{1} D_{2} \& 3^{-t y p e}$ cyclins[42]. In this regard, it is noteworthy that v-src, which phosphorylates STAT3 constitutively, has recently been found capable of transforming cells by activating the expression of cyclin $\mathrm{D}_{1}[44]$. It is now predictable that the identification of STAT inhibitors may well be very effective anti-cancer agents, and perhaps immunosuppressive agents as well.

\section{References}

I. Robb RJ, Smith KA: Heterogeneity of human T-cell growth factor(s) due to variable glycosylation. Mol Immunol 198I, 18:1087-1094.

2. Smith KA, Favata MF, Oroszlan S: Production and characterization of monoclonal antibodies to human interleukin 2: strategy and tactics. J Immunol I983, I3 I:1808-1815.

3. Robb RJ, Munck A, Smith KA: T cell growth factor receptors. Quantitation, specificity, and biological relevance. J Exp Med 198I, 154:| 1455- | 474.

4. Leonard WJ, Depper JM, Uchiyama T, Smith KA, Waldmann TA, Greene WC: A monoclonal antibody that appears to recognize the receptor for human T-cell growth factor; partial characterization of the receptor. Nature 1982, 300:267-269.
5. Sharon M, Klausner RD, Cullen BR, Chizzonite R, Leonard WJ: Novel interleukin-2 receptor subunit detected by cross-linking under high affinity conditions. Science 1986, 234:859-863.

6. Teshigawara K, Wang HM, Kato K, Smith KA: Interleukin 2 highaffinity receptor expression requires two distinct binding proteins. J Exp Med 1987, 165:223-238.

7. Tsudo M, Kozak RW, Goldman CK, Waldmann TA: Contribution of a p75 interleukin 2 binding peptide to a high-affinity interleukin 2 receptor complex. Proc Natl Acad Sci USA 1987, 84:4215-42। 8 .

8. Takeshita T, Ohtani K, Asao H, Kumaki S, Nakamura M, Sugamura K: An associated molecule, p64, with IL-2 receptor beta chain. Its possible involvement in the formation of the functional intermediate-affinity IL-2 receptor complex. J Immunol 1992, 148:2154-2।58.

9. Lambert G, Stura EA, Wilson IA: Crystallization and preliminary $X$-ray diffraction studies of a complex between interleukin-2 and a soluble form of the p55 component of the high affinity interleukin-2 receptor. J Biol Chem 1989, 264:I2730-12736.

10. Wang X, Rickert M, Garcia KC: Structure of the Quaternary Complex of Interleukin-2 with Its \{alpha\}, \{beta\}, and \{gamma\}c Receptors. Science 2005, 31 0: I I59-I I63.

II. Stauber D, Debler E, Horton P, Smith K, Wilson I: Crystal structure of the interleukin-2 signaling complex: paradigm for a heterotrimeric cytokine receptor. Proc Natl Acad Sci USA 2005 in press.

12. Bazan JF: Unraveling the structure of IL2. Science 1992, 257:410-4I3.

13. Langley J: On the physiology of the salivary secretion. J Physiol (Lond) 1878, I:339-369.

14. Langley J: On the reaction of cells and nerve endings to certain poisons, chiefly as regards the reaction of striated muscle to nicotine and to curari. J Physiol (Lond) 1905, 33:374-4I3.

15. Wang HM, Smith KA: The interleukin 2 receptor. Functional consequences of its bimolecular structure. J Exp Med 1987, 166:1055-1069.

16. Johnson K, Choi Y, Wu Z, Ciardelli T, Granzow R, Whalen C, Sana T, Pardee G, Smith K, Creasy A: Soluble IL2 receptor beta and gamma subunits: ligand binding and cooperativity. Eur Cytokine Netw 1994, 5:23-34.

17. Nelson B, Lord J, Greenberg P: Cytoplasmic domains of the interleukin-2 receptor beta and gamma chains mediate the signal for T-cell proliferation. Nature 1994, 369:333-336.

18. Russell S, Johnston J, Noguchi M, Kawamura M, Witthuhn B, Silvennoinen O, Goldman A, Schmalsteig F, Ihle J, O'Shea J, Leonard W: Interaction of IL2R beta and gamma-c chains with JAKI and JAK3: implications for XSCID and XCID. Science 1994, 266: $1042-1045$

19. Sugamura K, Asao H, Kondo M, Tanaka N, Ishii N, Nakamura M, Takeshita T: The common gamma chain for multiple cytokine receptors. Adv Immunol 1995, 59:225-277.

20. Asao H, Okuyama C, Kumaki S, Ishii N, Tsuchiya S, Foster D, Sugamura K: Cutting Edge: The Common \{\{gamma\}\}-Chain Is an Indispensable Subunit of the IL-2I Receptor Complex. J Immunol 200I, 167:I-5.

21. Lin J-X, Migone T-S, Tsang M, Friedmann M, Weatherbee JA, Zhou L, Yamauchi A, Bloom ET, Mietz J, et al:: The role of shared receptor motifs and common Stat proteins in the generation of cytokine plietropy and redundancy by IL2, IL4, IL7, IL I 3, and ILI 5. Immunity 1995, 2:33I-339.

22. Sana T, Wu Z, Smith K, Ciardelli T: Expression and ligand binding characterization of the beta subunit (p75) ectodomain of the interleukin-2 receptor. Biochem 1994, 33:5838-5845.

23. Wu Z, Johnson KW, Goldstein B, Choi Y, Eaton SF, Laue TM, Ciardelli TL: Solution Assembly of a Soluble, Heteromeric, High Affinity Interleukin-2 Receptor Complex. J Biol Chem 1995, 270:16039-16044.

24. Wu Z, Johnson KW, Choi Y, Ciardelli TL: Ligand Binding Analysis of Soluble Interleukin-2 Receptor Complexes by Surface Plasmon Resonance. J Biol Chem 1995, 270:16045-1605I.

25. Wu Z, Goldstein B, Laue TM, Liparoto S, Nemeth M, Ciardelli T: Solution assembly of the pseudo-high affinity and intermediate affinity interleukin-2 receptor complexes. Protein Sci 1999 , 8:482-489.

26. Liparoto $\mathrm{S}$, Ciardelli $\mathrm{T}$ : Biosensor analysis of the interleukin-2 receptor complex. J Mol Rec 1999, 12:316-321. 
27. Liparoto SF, Myszka DG, Wu Z, Goldstein B, Laue TM, Ciardelli TL: Analysis of the Role of the Interleukin-2 Receptor Gamma Chain in Ligand Binding. Biochemistry 2002, 4I:2543-255I.

28. Smith KA, Cantrell DA: Interleukin 2 regulates its own receptors. Proc Natl Acad Sci USA 1985, 82:864-868.

29. Smith KA: The interleukin 2 receptor. Annu Rev Cell Biol 1989, 5:397-425.

30. Cantrell DA, Smith KA: The interleukin-2 T-cell system: a new cell growth model. Science 1984, 224: $13 \mid 2-1316$.

31. Smith K: The quantal theory of how the immune system discriminates between "self and non-self". Med Immunol 2004, 3:3.

32. Smith K: The quantal theory of immunity. Cell Res 2006, 16:11-19.

33. Rickert M, Boulanger M, Goriatcheva N, Garcia K: Compensatory energetic mechanisms mediating the assembly of signaling complexes between interleukin 2 and its alpha, beta and gamma receptors. J Mol Biol 2004, 339: I I I5- I I 28.

34. Rickert M, Wang X, Boulanger M, Goriatcheva N, Garcia K: The structure of interleukin-2 complexed with its alpha receptor. Science 2005, 308: 1477-I480.

35. Ku C, Murakami M, Sakamoto A, Kappler J, Marrack P: Control of homeostasis of CD8+ memory T cells by opposing cytokines. Science 2000, 288:675-678.

36. Boyman O, Kovar M, Rubinstein M, Surh C, Sprent J: Selective stimulation of $\mathbf{T}$ cell subsets with antibody-cytokine immune complexes. Science 2006, 3 I I: 1924-1927.

37. Smith K: Interleukin $\mathbf{2}$ Immunotherapy. In Therapeutic Immunology 2nd edition. Edited by: Austen F, Burakoff S, Rosen F, Strom T. Malden, MA: Blackwell Science, Inc.; 200I:240-250.

38. Yao Z, Cui Y, Watford WT, Bream JH, Yamaoka K, Hissong BD, Li D, Durum SK, Jiang Q, Bhandoola A, et al.: Stat $5 \mathrm{a} / \mathbf{b}$ are essential for normal lymphoid development and differentiation. PNAS 2006, 103:1000-1005.

39. Hoelbl A, Kovacic B, Kerenyi MA, Simma O, Warsch W, Cui Y, Beug $\mathrm{H}$, Hennighausen L, Moriggl R, Sexl V: Clarifying the role of Stat5 in lymphoid development and Abelson-induced transformation. Blood 2006, 107:4898-4906.

40. Zmuidzinas A, Mamon HJ, Roberts TM, Smith KA: Interleukin 2triggered Raf-I expression, phosphorylation, and associated kinase activity increase through $\mathrm{GI}$ and $\mathrm{S}$ in CD3-stimulated primary human T cells. Mol Cell Bio I99I, I I:2794-2803.

41. Moon J, Rubio E, Martino A, Krumm A, Nelson B: A permissive role for phophatidylinositol 3-kinase in the STAT5-mediated expression of cyclin D2 by the interleukin-2 receptor. J Biol Chem 2004, 279:5520-5527.

42. Moriggl R, Topham DJ, Teglund S, Sexl V, McKay C, Wang D, Hoffmeyer A, van Deursen J, Sangster MY, Bunting KD, et al.: Stat5 is required for IL-2-induced cell cycle progression of peripheral T cells. Immunity 1999, 10:249-259.

43. Moriggl R, SexI V, Piekorz R, Topham D, Ihle J: Stat5 activation is uniquely associated with cytokine signaling in peripheral $\mathbf{T}$ cells. Immunity 1999, I I:225-230.

44. Leslie K, Lang C, Devgan G, Azare J, Berishaj M, Gerald W, Kim Y, Paz $\mathrm{K}$, Darnell J, Albanese C, et al.: Cyclin DI is transcriptionally regulated by and required for transformation by activated signal transducer and activator of transcription 3. Cancer Res 2006, 66:2544-2552.

\section{Publish with Biomed Central and every} scientist can read your work free of charge

"BioMed Central will be the most significant development for disseminating the results of biomedical research in our lifetime. "

Sir Paul Nurse, Cancer Research UK

Your research papers will be:

- available free of charge to the entire biomedical community

- peer reviewed and published immediately upon acceptance

- cited in PubMed and archived on PubMed Central

- yours - you keep the copyright
BiolMedcentral 